\title{
Cognitive Framing Illusions and Consumer Rationality
}

\author{
Isaiah Deng ${ }^{1}$ and Pi-Sheng Deng*,2 \\ ${ }^{I}$ Department of Economics, University of California at Berkeley, Berkeley, CA 94720-3880, USA; ${ }^{2}$ Department of \\ Computer Information Systems, California State University at Stanislaus, Turlock, CA 95382, USA
}

\begin{abstract}
This paper attempts to determine if consumers realistically behave rationally when making choices under cognitive framing illusions. In addition, we demonstrate how cognitive framing illusions can be utilized by firms to earn profit. The paper furthermore details why the framing 7illusion variable cannot be displayed by itself - to work, it must be shown with the rest of the bargain. The double discount effect investigated in this paper is simply one of the myriads of cognitive framing illusions firms can utilize to pave their path to effective marketing management. The results from the field research can be useful or practical for future research regarding this topic. Cognitive framing could be expanded past illusions, to include an array of perceptive and psychological aspects of human behavior - how the consumer views not only economic choices, but also how he or she views the world.
\end{abstract}

Keywords: Behavioral economics, bounded rationality, congitive framing illusions, consumer irrationality, double discout effect, impulse purchasing, irrationally-oriented consumers, rationally-oriented consumers.

\section{INTRODUCTION}

As the basic framework for determining price and output through supply and demand, neo-classical economics rests on the assumptions that individuals maximize their incomeconstrained utility, via a "rational" process. Over the past five decades, however, economists have generated models of bounded rationality $[1,2]$ for the purposes of providing a more realistic and psychologically plausible conception which states that individuals experience informational and cognitive limitations of the mind [3,4]. It is this perception that embodies the essence of behavioral economics the integration of psychology into neo-classical economics.

The objective of this paper is to conduct a study of the framing branch of behavioral economics; a branch that explores how the way in which a decision is presented to the decision maker affects his or her choice [5]. Following a discussion of how various cognitive framing illusions instigate irrational consumer behavior, we will propose a theory that establishes a common baseline within each cognitive framing illusion, derive a new framing illusion based on this theory, and test its effectiveness in a field experiment that will ascertain either its success or failure. Existing literature on this issue has not delved into the generating of a common baseline theory for cognitive framing illusions, and thus may not be sufficient to answer this question.

The paper is organized as follows: Section 2 discusses findings from both behavior economics and marketing rationale literature - elements that are dispersed throughout the essay. Section 3 details four common cognitive framing illusions that have been shown to prompt consumer irrationality. Section 4 presents the common baseline theory, and Section 5 covers the research procedure utilized

*Address correspondence to this author at the Department of Computer Information Systems, California State University at Stanislaus, Turlock, CA 95382, USA; Tel: (209) 667-3018; E-mail: pdeng@csustan.edu

1874-9488/11 for testing its effectiveness. Section 6 displays data results and an analysis of the data results. Section 7 then implements the data results in an evaluation of their economic significance, and Section 8 concludes the paper with a broad overview and synopsis.

\section{LITERATURE REVIEW}

In order to sufficiently answer our question, it is important to gather information not only from the consumer's perspective with behavior economics, but from the seller's standpoint with marketing literature as well.

Firstly, why should firms and organizations be concerned with behavioral economics? Consumer behavior is one of the many branches that constitute behavioral economics. The study of consumers and their actions help businesses largely improve their marketing strategies by understanding a variety of issues. Based on Reder's work [6], such issues entail the psychology of how consumers reason and choose between different brands or products, how the consumer is affected by the immediate environment, such as sale signs or store decorations, or how the buyer is constrained by natural limitations in consumer knowledge and information processing capacity. Consumers therefore can often fall prey to irrational choices.

What factors then exemplify consumer irrationality? According to studies by Hoyer [3], the decision process of a consumer is largely influenced by impulse purchasing - an occurrence that is typified by consumers abruptly deciding to purchase something they had not planned on buying initially. Hoyer [3] states that psychology plays a role in that impulse purchases can be characterized by overwhelming feelings of having to buy the product instantly - feelings so strong, in fact, that they overwhelm potentially negative purchase consequences. Such impulse purchasing is often triggered by the consumer's exposure to an external stimulus, which can range from store discount displays, advertisements, or appealing visual product presentation. The consumer thus 
demonstrates an absence of rationality if he or she is influenced by impulse purchasing. Irrationality then prevails within myriads of consumers, as records show that approximately $63 \%$ of shoppers buy at least one unplanned item out of impulse [3].

The marketing implications of consumer irrationality are then highly connected with impulse purchasing - research by Berkman [7] has shown that many stores arrange or frame their products in such a way that consumers' impulse purchasing is maximized. For instance, stores may put products at eye level, surround products with aesthetically pleasing decorations, or implement point-of-purchase displays - the strategic placement of the smallest and cheapest products near the check-out line. In-store demonstrations, store atmosphere, and even salespeople can hold a huge influence over unplanned purchasing. The simple act of taking advantage of consumer impulses can increase sales and profits dramatically - firms should therefore spend a considerable amount of time deliberating how to encourage unplanned purchases at point of sale.

Studies by Murphy [8], however, provide a more indepth analysis of factors that influence impulse buying. Murphy [8] proposes that impulse purchases are prompted by both the consumers' inability to control themselves, and their natural traits. In fact, the tendency to purchase on impulse can be correlated with other traits, such as "general acquisitiveness and materialism, sensation seeking, and a liking for recreational shopping [8]."

The framing effect in psychology and economics provides yet another explanation for decision-makers' impulse purchases. Studies by Tversky \& Kahneman [5] and Biswas \& Grau [4] convey how the context or framing of options plays a significant role in determining the outcome of choice problems - sometimes even to the point where conventional theories of rational choice no longer exist. The experiment that Kahneman \& Tversky [9] carry out reveal that a simple change in the framing of options resulted in a preference reversal amongst subjects. This is empirically supported by the experiment conducted by Biswas \& Grau [4] in which consumers were found to choose a higher number of product options when starting from a fully loaded model rather than a base model.

Furthermore, Gilbride, Guiltinan \& Urbany [10] investigate whether price framing affects choice in mixed price bundles. Price framing effects refer to the way in which the price of a bundle is presented to the consumer. They find that the joint, integrated frame results in the highest proportion of respondents purchasing the bundle. On the other hand, as the prices of items in a bundle are itemized, consumers tend to compare prices separate from their reference prices when evaluating the attractiveness of the deal. This typically reduces the probability of purchasing the bundle. However, Janiszewski \& Cunha [11] argue for the effects of reference prices. They claim that the perceived value of the bundle may depend on reference prices for each product item, and that price framing is more effective when applied to the product that will receive the most weight in the overall evaluation of the bundle.

\section{COGNITIVE FRAMING ILLUSIONS}

Since the studies of Kahneman and Tversky [9] regarding the framing effect, the field of cognitive framing has expanded [2]. In order to observe whether consumers behave rationally when confronted with cognitive framing illusions, we will focus on three experimental studies that have tested various types of framing illusions on subjects.

First, the "Useless Option Illusion" was exclusively tested by Ariely [12] on MIT students. These students were given three options and were told to select the option that they thought was best. The options were: (1) Online Subscription of The Economist for \$59.00, (2) Print Subscription of The Economist for $\$ 125.00$, or (3) Both Online and Print Subscriptions of The Economist for $\$ 125.00$. The results were drastic $-84 \%$ of the students chose Option 3, and the remaining 16\% chose Option 1. Yet, when the middle option (Option 2) was taken out and subjects were retested, results took a complete turnaround $68 \%$ now chose Option 1, while only $32 \%$ chose Option 3.

As Ariely's studies [12] depicted, Option 2 was indeed "useless," in that no one selected it - but in reality, it was substantially functional in that it played the role of a decoy, being the primary factor that caused subjects to change their minds. What caused consumer irrationality in this case? The strategic placement of Option 2 directly next to Option 3 almost certainly was the instigator, as it created the illusion that Option 3 was an incredible bargain that could not be passed up. Yet when the middle option disappeared, the illusion vanished. Subjects now only saw the acute difference between two prices - $\$ 59$ and $\$ 125$ - and naturally opted away from the more expensive deal, which was more than two times as costly as the first option.

The second framing illusion entails the "99 Cent Illusion," where firms price items at, for instance, $\$ 19.99$ as opposed to \$20. Many studies [13-15] have shown that consumers spend more money when prices end in 9 - but theories explaining why vary. The mainstream theory states that when individuals process information, the first number they read exercises much higher influence than the following numbers $[14,16]$. Thus, the numerical value of 19 being less than 20 gives the illusion that the first price is a much better deal than the second, despite the difference merely being 1 cent.

A third framing illusion comes from the conventional sales promotion "buy one get one free" deal. Consumers typically assume that all they need to do is purchasing the item, and they will receive another free - a pleasantly tempting bargain. Yet studies have shown that these promotions render profits for the selling firm because the "discounted" new price essentially takes into account the fact two items are being sold [17]. The price of buying the first product is usually raised - but by placing it in a "buy one get one free" deal, consumers might even be more susceptible to buy the product as the price increases.

A possible reason for this contradictory positive correlation between price and quantity demanded can be attributed to the consumers' illusion that they are potentially saving more if the product is more expensive. For instance, the consumer may assume that purchasing a $\$ 1.00$ candy bar 
under a "buy one get one free" deal saves them $\$ 1$ - buying each separately under what they believe to be normal conditions would have cost $\$ 2$. Therefore, purchasing a $\$ 50$ microwave under the same deal would save them \$50much more than if they had purchased the significantly cheaper item. Additionally, if the purchased product is an item that the buyer does not necessarily need two of, then the firm has successfully led the consumer to buy on pure impulse rather than rationale.

\section{COMMON BASELINE THEORY}

The three cognitive framing examples discussed above shared a significant mutual characteristic - each comprised of an "illusion variable" - a factor that prompted consumers to behave irrationally by causing them to select what they believed to be the better bargain, when in reality it was not. The role of the illusion variable was essentially to diminish the effect of the rest of the bargain. For instance, the illusion variable of "get one free" moderated the negative impressions derived from "buy one." Similarly, the illusion variable of the useless middle option reduced the impact of the more expensive option, and the illusion variable of " $\$ 19$ " being less than $\$ 20$ minimized the effects of the 99 cents that followed it.

We can thus derive a new framing illusion by the same process. First, we must establish two arbitrary bargains, $\beta$ and $¥$. If we set $\beta$ as the bargain that we do not want the consumer to choose, despite it being the better bargain, then $¥$ will be our illusion variable. In other words, we need to generate $\beta$ and $¥$ such that the impact of $¥$ minimizes the effect of $\beta$. Because $\beta$ can be a random bargain, let us set $\beta=$ a $65 \%$ discount off a $\$ 100.00$ item. In this situation, our illusion variable $¥$ therefore must satisfy two conditions: (1) in reality it is a worse bargain than $\beta$, and (2) it appears to be a better bargain than $\beta$. Although there are many ways to approach this, one of the more effective methods may be to take advantage of the fact that many individuals are not competent at mathematics or calculations [16].

Implementing a variation of the double discount method would satisfy both conditions for $¥$. Suppose $¥=$ a $30 \%$ discount off a $\$ 100$ item, with an additional $40 \%$ discount taken off at the register. By breaking the discount into two separate "discount deals," we have created the illusion that $¥$ is the better bargain to individuals who simply add the $30 \%$ to the $40 \%$ and assume that they are getting $70 \%$ off the item - a bargain that is much more preferable to the $65 \%$ discount deal. Yet in reality, $¥$ is a much worse bargain than $\beta$. Related calculations regarding total costs under each bargain are as follows:

$$
\begin{aligned}
\text { Bargain } \beta: \text { Total Cost to Consumer }= & \$ 100-(\$ 100 \times 0.65)=\$ 35 \\
\text { Bargain } ¥: \text { Total Cost to Consumer }= & \$ 100-(\$ 100 \times 0.30)=\$ 70 \\
& \$ 70-(\$ 70 \times 0.40)=\$ 42
\end{aligned}
$$

Thus, the consumer actually only pays $\$ 35$ under $\beta$, as opposed to paying $\$ 42$ under $¥$. This theory nonetheless must be tested in field research to confirm its validity and effectiveness.

\section{RESEARCH PROCEDURE}

Field research encompassed a range of four days,

\begin{tabular}{|c|c|c|}
\hline & Procedure & Method \\
\hline Days 1-4 & $\begin{array}{l}\text { Pose the two-bargain } \\
\text { option questionnaire } \\
\text { discussed in Section } \\
\text { IV to randomly } \\
\text { selected subjects, until } \\
200 \text { responses have } \\
\text { been obtained. }\end{array}$ & $\begin{array}{l}\text { In-person ques- } \\
\text { tionnaire with } \\
\text { randomly se- } \\
\text { lected partici- } \\
\text { pants } \\
\text { Online ques- } \\
\text { tionnaire via } \\
\text { Email, Face- } \\
\text { book, and } \\
\text { MySpace. }\end{array}$ \\
\hline Key Assumptions & \multicolumn{2}{|c|}{$\begin{array}{l}\text { We assume that all subjects (from } \\
\text { both in-person questionnaires and on- } \\
\text { line questionnaires) thoroughly read } \\
\text { and answer the question genuinely } \\
\text { based on what they believe is the cor- } \\
\text { rect answer. In other words, we as- } \\
\text { sume that none of the subjects simply } \\
\text { guess/jot down an answer without } \\
\text { thinking or reading the question. } \\
\text { We assume that all subjects that an- } \\
\text { swered the questionnaire online an- } \\
\text { swer the question by themselves } \\
\text { (without assistance from other peo- } \\
\text { ple). } \\
\text { We assume that answers by any sub- } \\
\text { ject is not affected by whether the } \\
\text { questionnaire was done in-person or } \\
\text { online. }\end{array}$} \\
\hline Other Notes & \multicolumn{2}{|c|}{$\begin{array}{l}\text { - For convenience purposes, Bargain } \beta \\
\text { is denoted as }(A) \text {, and Bargain } ¥ \text { is } \\
\text { denoted as }(B) \text {. } \\
\text { The majority of responses that are } \\
\text { listed in our data results came from } \\
\text { the online questionnaire. Although all } \\
\text { of the online questionnaires were sent } \\
\text { to friends, this should not create a } \\
\text { source of bias, as each person's } \\
\text { choice is unique, and there is no in- } \\
\text { centive that induces the participant to } \\
\text { select a particular answer. } \\
\text { The only difference between the exe- } \\
\text { cutions of questioning was that online } \\
\text { respondents saw the question in its } \\
\text { entirety and the 'Big Sale' sign (see } \\
\text { Appendix A for reference), whereas } \\
\text { in-person respondents were read the } \\
\text { question orally and thus could not see } \\
\text { the question or the sign visually un- } \\
\text { less they requested. However, none of } \\
\text { the in-person respondents made this } \\
\text { request. }\end{array}$} \\
\hline
\end{tabular}
comprising of 200 tested subjects. The raw data procedure is displayed in the chart below.

${ }^{1}$ The exact text from the surveys utilized in field research is listed in the Appendix section. 
The proposed two-bargain option questionnaire was thus dispersed in-person and online until 100 subject responses for each method were obtained. Note that our in-person questionnaire method simulates the realistic situation in which a shopper walks inside a store and spots the signs of the two different discount options, as displayed in said questionnaire. On the other hand, the online questionnaire is more comparable to the scenario in which individuals receive advertisement via embodiment of mail or various online media, therefore allowing them to calculate and compare discounts more carefully with their own reference prices, given the extended discretionary time allotment.

Measure of effectiveness of the newly proposed cognitive framing illusion will be calculated as follows: if

$$
\frac{(\# \text { of respondents who selected } B)}{(\text { Total } \# \text { of respondents })} \geq \frac{(\# \text { of respondents who selected } A)}{(\text { Total } \# \text { of respondents })},
$$

then the framing illusion will be considered successful and effective in inducing most shoppers' irrationality. As stated above, "\# of respondents who selected $B$ " refers to those who chose Bargain $¥$, and "\# of respondents who selected $A$ " refers to those who picked Bargain $\beta$.

The degree of a shopper's rationality, under the influence of framing illusions, can be conceptually measured along a continuum ranging from 0 to 1 as follows:

(1) If shoppers were completely rational, then every respondent would have chosen the truly better option $A$, and thus

$\frac{(\# \text { of respondents who selected } A)}{(\text { Total } \# \text { of respondents })}=100 \%$ and

$\frac{(\# \text { of respondents who selected } B)}{(\text { Total } \# \text { of respondents })}=0 \%$.

(2) If shoppers were completely irrational, then every respondent would have chosen the seemingly better option $B$, and thus

$\frac{(\# \text { of respondents who selected } B)}{(\text { Total } \# \text { of respondents })}=100 \%$ and

$\frac{(\# \text { of respondents who selected } A)}{(\text { Total } \# \text { of respondents })}=0 \%$.

(3) If shoppers are boundedly rational or semi-rational, then some shoppers will prefer option $A$, while others will prefer option $B$. This case renders:

$$
\begin{gathered}
0 \%<\frac{(\# \text { of respondents who selected } A)}{(\text { Total } \# \text { of respondents })}<100 \% \text { and } \\
0 \%<\frac{(\# \text { of respondents who selected } B)}{(\text { Total } \# \text { of respondents })}<100 \% .
\end{gathered}
$$

(4) We define that shoppers are rationally-oriented if $\frac{(\# \text { of respondents who selected } A)}{(\text { Total } \# \text { of respondents })}>\frac{(\# \text { of respondents who selected } B)}{(\text { Total } \# \text { of respondents })}$.

(5) On the other hand, shoppers are irrationally-oriented if

$$
\frac{(\# \text { of respondents who selected } B)}{(\text { Total } \# \text { of respondents })} \geq \frac{(\# \text { of respondents who selected } A)}{(\text { Total } \# \text { of respondents })} \text {. }
$$

If the formula above holds true, then we can determine that the majority of the subjects in our field experiment have chosen irrationally.

Results from this study allow us to judge whether the common baseline theory we have established is plausible. If so, we can additionally calculate how firms can use this theory to gain profit. We will apply this reasoning in Section 6 through a discussion of the economic relevance to cognitive framing illusions and consumer irrationality.

\section{DATA PROCESSING AND ANALYSIS}

With regards to the collection of data over the four-day field research, the results of the findings collected from the first 200 respondents (100 from in-person interviews, 100 from the online questionnaire) are displayed in a $2 \times 2$ contingency table as shown in Table 1. Respondents of the in-person questionnaires undergo the assumed commonplace scenario of in-store shoppers, in that they must make their decisions on the spot.

In order to investigate if the choice of $A$ or $B$ is influenced by different methods of data collection, we will

\begin{tabular}{|c|c|c|c|}
\hline & $\begin{array}{c}\text { Number of In- } \\
\text { person } \\
\text { Respondents }\end{array}$ & $\begin{array}{l}\text { Number of } \\
\text { Online } \\
\text { Respondents }\end{array}$ & Total \\
\hline $\begin{array}{c}\text { Chose } A \\
(\boldsymbol{\beta})\end{array}$ & 40 & 59 & 99 \\
\hline $\begin{array}{c}\text { Chose } B \\
\text { (サ) }\end{array}$ & 60 & 41 & 101 \\
\hline Total & 100 & 100 & 200 \\
\hline
\end{tabular}
apply the $\chi^{2}$ test to perform a test of independence between these two factors.

Table 1. A $2 \times 2$ Contingency Table

Based on Table 1, $\chi^{2}=7.22$ and the degree of freedom $(d f)$ is: $(2-1)(2-1)=1$. Since $\chi_{0.99(1)}^{2}=6.635, \chi^{2}>\chi_{0.99(1)}^{2}$. Thus, we can conclude that the data collection method does affect respondents' choice of discount options. In other words, respondents of different data collection methods show different levels of rationality in their decisions.

An effective examination of the data established thus far can be implemented through visual representations, by allowing a quick and easy comparison between data sets. The compiled data results regarding spread of information can be represented by the following line graph as shown in Fig. (1). 


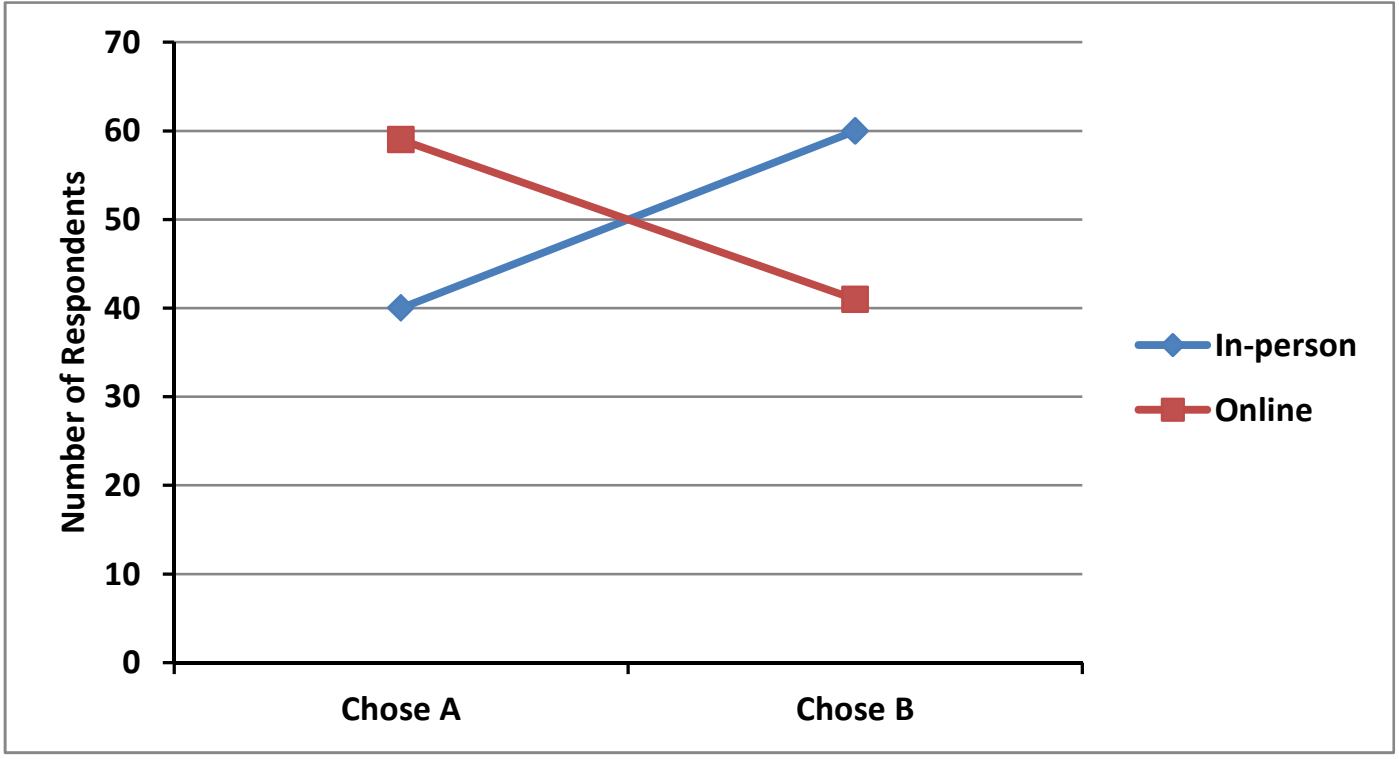

Fig. (1). Frequency comparison between $A$ and $B$ for different data collection methods.

Fig. (1). shows that most of the respondents who received the in-person questionnaires favored $B$. On the other hand, most of the respondents who received the online questionnaires favored $A$. This seems to indicate that respondents of in-person questionnaires tend to be subject to the influence of framing illusions more than those of online questionnaires.

In order to understand if the framing illusion significantly affects a shopper's level of rationality, we continue to apply the $\chi^{2}$ test to look into the decisions made by respondents of each method. The choices made by the respondents of the inperson questionnaire are given in Table 2:

Table 2. Decisions Made by Respondents of In-Person Questionnaire

\begin{tabular}{|c|c|c|}
\hline & $\begin{array}{c}\text { Number of } \\
\text { Respondents }\end{array}$ & $\begin{array}{c}\text { \% of Respondents for } \\
\text { selections } A \text { and } \boldsymbol{B}\end{array}$ \\
\hline $\begin{array}{c}\text { Chose } A \\
(\boldsymbol{B})\end{array}$ & 40 & $40 / 100=40 \%$ \\
\hline $\begin{array}{c}\text { Chose } B \\
(¥)\end{array}$ & 60 & $60 / 100=60 \%$ \\
\hline
\end{tabular}

The computed $\chi^{2}$ value based on Table 2 is: $\chi^{2}=4.00$. When $d f=1$ and the level of significance $\alpha=0.05$, we have $\chi_{0.95(1)}^{2}=3.841$. Since the computed $\chi^{2}>\chi_{0.95(1)}^{2}$, we know that framing illusion has a significant effect in causing consumers' irrationality. As seen from the data results, the difference between the numbers of subjects who selected $B$ over $A$ was obvious. Since $60 \%>40 \%$, the following statement holds true that with the effect of framing illusion:

$\frac{(\# \text { of respondents who selected } B)}{(\text { Total } \# \text { of respondents })} \geq \frac{(\# \text { of respondents who selected } A)}{(\text { Total } \# \text { of respondents })}$.
The common baseline theory we have established earlier is therefore verified. The framing illusion variable does affect an in-store shopper's level of rationality, and thus also influences a shopper's tendency of impulse purchasing. In other words, an in-store shopper tends to be irrationallyoriented under the influence of framing illusion.

We also investigate how the respondents who received online questionnaires responded to the framing illusion. The result of the online questionnaire is shown in Table 3 :

Table 3. Decisions Made by Respondents of Online Questionnaire

\begin{tabular}{|c|c|c|}
\hline & $\begin{array}{l}\text { Number of } \\
\text { Respondents }\end{array}$ & $\begin{array}{c}\% \text { of Respondents for } \\
\text { selections } A \text { and } B\end{array}$ \\
\hline $\begin{array}{c}\text { Chose } A \\
(B)\end{array}$ & 59 & $59 / 100=59 \%$ \\
\hline $\begin{array}{c}\text { Chose } B \\
\text { (I) }\end{array}$ & 41 & $41 / 100=41 \%$ \\
\hline
\end{tabular}

The majority of the online-questionnaire respondents seemed to choose more rationally than the other group of respondents. To understand if the difference was significant or not, we calculated, based on Table $3, \chi^{2}=3.24$. Since $\chi^{2}<$ $\chi_{0.95(1)}^{2}$, though $\chi^{2}>\chi_{0.90(1)}^{2}$, there is no sufficient evidence to support the claim that there is a significant effect (at $95 \%$ or higher confidence level) of framing illusion existent amongst online respondents.

A variety of hypotheses may be proposed to explain these results. The most palpable explanation would simply be that cognitive framing illusion causes consumers to make irrational decisions. Option $B(¥)$ comprised of the illusion that the double discounts added to $70 \%$. By framing $¥$ directly alongside a deal that is slightly lower in value $65 \%$ we have made the comparison more evenhanded. For 
instance, if Option $A$ (Bargain $\beta$ ) had been "a $59 \%$ discount off a $\$ 100.00$ item," the customer may have been more wary about choosing Option $B$ (Bargain $¥$ ) - the blatantly large difference between $70 \%$ and $59 \%$ may instigate a "too good to be true" customer rationale. Establishing Option $A$ as $65 \%$ allows for easy computation and a smaller difference.

However, before rushing to conclusions, it is imperative to note elements of observable error. The raw data of the field research does not come without potential sources of bias, as the minimization of these biases could have triggered an alteration of results. For instance, if the majority of the questionnaire responses came from online, answers are biased towards the more rational choice, $A$, assuming the participant has ample time to read, re-read, comprehend and answer the question fully at their own pace. Whereas, if the majority of the questionnaire responses had come from inperson interviews, we would expect more selections of the irrational choice, $B$. This is because the participant now must answer the question "on the spot," without the luxuries of the unlimited timeframe for answering that online respondents had.

Another potential source of error comes from the different methods of information diffusion or execution, as briefly discussed in the Research Procedure. It is possible that the online participants were influenced by the "Big Sale" sign on the Field Experimentation card, thereby rushing to the conclusion that the process was a simple mathematical assessment regarding basic addition skills. If so, the online participant would immediately add the $30 \%$ to the $40 \%$ without thinking twice about it, and ultimately conclude that Option $B$ was the more superior bargain, based on the reasoning that $70 \%$ was larger than $65 \%$.

One further potential bias comes within the word structuring of the questionnaire itself. In the questionnaire, Option $B$ reads "a $30 \%$ discount off the same $\$ 100.00$ item, with an additional $40 \%$ discount taken off at the register." The mere word "additional" may have triggered participants, online and in-person alike, to interpret Option $B$ as the mathematical operation of addition. Therefore, if the word "additional" had been replaced by other synonyms such as "another," or even "extra," we could anticipate a more careful analysis of the problem, and subsequently more selections of Option $A$.

\section{THE ROLE OF ECONOMICS IN COGNITIVE FRAMING ILLUSIONS}

Based on our field research results, cognitive framing illusions and their impact on consumer behavior retain huge economic implications and relevance. Suppose a competitive shoe company has just come out with a brand new model of a shoe, and is contemplating how to price it before bringing it out. Suppose also that the firm's total production cost for manufacturing each pair of these new shoes is $\$ 35$, and the firm decides to use an unconventional pricing method letting the in-store customers themselves choose what they pay. Specifically, the consumers are given the exact options that were utilized in our field research (Options $A$ and $B$ in the Appendix). The firm figures that because customers do not know this initial production cost, they can set an exorbitantly high initial price for each pair of shoes (considerably higher than their production costs) and add a large discount to induce the illusion of an appealing bargain. With the given circumstances, the firm can make a certain amount of profit. Related calculations that prove this statement true are as follows:

\begin{tabular}{|c|c|}
\hline & 1. Total production cost per pair of shoes $=\$ 35$ \\
\hline $\begin{array}{c}\text { Cost } \\
\text { Assumptions }\end{array}$ & $\begin{array}{l}\text { 2. Firm states that initial price per pair of shoes }= \\
\$ 100 \text {, but gives consumers a choice of }(A) \text { a } \\
65 \% \text { discount off the } \$ 100 \text { pair of shoes, or }(B) \text { a } \\
30 \% \text { discount off the same } \$ 100 \text { pair of shoes, } \\
\text { with an additional } 40 \% \text { discount taken off at the } \\
\text { register. }\end{array}$ \\
\hline
\end{tabular}

According to our analysis performed in section 6, the framing illusion is significantly effective amongst respondents who received the in-person survey. The further analysis presented in this section is for the case of in-store shoppers. Assume there are 100 in-store customers choose to purchase these new pairs of shoes, based on our field research data results, we can expect to see 40 out of the 100 select discount option $A$, and 60 out of the 100 pick discount option $B$. Therefore,

Firm's Total Profit $=$ Total Revenue - Total Cost

$$
=((40 \times \$ 35)+(60 \times \$ 42))-(100 \times \$ 35)
$$

[See footnote for explanation of the above calculations] ${ }^{2}$

$$
\begin{aligned}
& =\$ 1400+\$ 2520-3500 \\
& =\$ 420
\end{aligned}
$$

Thus, by implementing this particular pricing strategy, the firm is able to make a profit of $\$ 420$ for selling 100 pairs of shoes. The bulk of this profit comes from the 60 customers selecting Option $B$. It is essential to note one may come to the quick conclusion that if the firm simply sold the item under discount Option $B$ (as opposed to giving customers a choice between discount Option $A$ and discount Option $B$ ), the resulting profit would still be the same ${ }^{3}$. However, this thought process is erroneous, in that the number of individuals who chose Option $B$ may have been dependent on their viewing of Option $A$.

In other words, customers who ended up choosing Option $B$ may have ultimately chosen to purchase the shoes for a variety of reasons, such as attraction to the freedom of discount choices that the firm gave, or comparison of the two options which led to the irrational decision that Option $B$ was a bargain that could not be passed up. Therefore, had the firm sold the innovative product solely at discount Option $B$ (Option $A$ does not exist in this case), the number of customers that would have actually purchased the product may be less than the number that would have bought the

\footnotetext{
${ }^{2}$ Recall that from our previous discussion of the two options, under Bargain $A(\beta)$, Total Cost to Customer $=\$ 100-(\$ 100 \times 0.65)=\$ \mathbf{3 5}$, and under Bargain $B(\nexists)$, Total Cost to Customer $=\$ 100-(\$ 100 \times 0.30)=\$ 70$ $\$ 70-(\$ 70 \times 0.40)=\$ 42$

Thus, $\$ 35$ is the revenue the firm gets for each sold pair of shoes under Bargain $A$, and $\$ 42$ is the revenue the firm receives for each sold pair of shoes under Bargain $B$. The firm's total cost is then the Total production cost of each pair of shoes $\times$ Total \# of pairs of shoes (which is 100 , in this case).

${ }^{3}$ Selling solely under the option $B$ discount (not giving consumers a choice), profit =
} $\mathrm{TR}-\mathrm{TC}=(60 \times \$ 42)-(60 \times \$ 35)=\$ 2520-\$ 2100=\$ 420$. 
product when given the liberty to choose between Options $A$ and $B$.

\section{CONCLUSION}

In conclusion, this paper attempts to determine if consumers realistically behave rationally when making choices under cognitive framing illusions. From this research process, we are able to conclude that consumers commonly behave irrationally when encountering such illusions, and can establish a common baseline theory embodying the framework of most cognitive illusions to generate new ones. This paper covers common examples of cognitive framing illusions, and additionally demonstrates how cognitive framing illusions can be utilized by firms to earn profit. This paper furthermore details why the framing illusion variable cannot be displayed by itself - to work, it must be shown with the rest of the bargain.

Consumer behavior thus plays a significant role in shaping marketing management. The double discount effect is simply one of the myriads of cognitive framing illusions firms can utilize to pave their path to success. The empirical study by Landa \& Wang [18] demonstrates the effects of the task environments on a decision maker's bounded rationality. Store layout, atmosphere, price reductions, pointof-purchase displays, and even demonstrations or shelving techniques are all additional methods that firms can utilize to trigger unplanned purchases - and ultimately, consumer irrationality. Our study shows that there was a significant difference (at the 99\% significance level) between the inperson and online surveys in affecting a shopper's choice of discount option. Furthermore, our analysis also demonstrates that framing illusion significantly (at the 95\% significance level) affected in-store shoppers' choices of discount options. On the other hand, the same illusion technique did not significantly affect (at the 95\% significance level) the decisions of online respondents.

The double discount illusion presented in our research can be applied to the sale of two competing product items, where consumer demand is large for one and small for the other. Displaying the products side by side such that consumers see both at the same time, one could then theoretically increase the sales of the lagging product by simply posting the sign of a $65 \%$ discount $(\beta)$ with the faster selling item, while posting the sign of double discount $(¥)$ with the slower selling item. Based on the analysis of this study, we would expect to see a resulting increase in sales for the originally slower selling item. This would increase the turn-around rate of inventory, ultimately raising profit for the store.

One limitation of this research lies within the fact that data were collected from a sample population where most ages were between 20 and 40, thereby introducing a potential bias into the research results. Further research can be conducted by studying how demographic factors, such as gender, age, level of education, race, or location (suburban or urban), affect consumers' choices in selecting discount options. Additionally, we can investigate how the order of presentation for discount options will affect consumers' choices. We can furthermore analyze the insensitivity region for different discount options and investigate if there is a significant difference among different types of media employed, such as Facebook, Twitter, MySpace, and email. This can help companies strategically decide which framing technique to optimally employ for their marketing campaign or sales promotion.

Although many aspects of this paper have been structured upon theories, assumptions, and data bias, the results from the field research can be useful or practical for future research regarding this topic. Cognitive framing could be expanded past illusions, to include an array of perceptive and psychological aspects of human behavior - how the consumer views not only economic choices, but also how he or she views the world.

\section{APPENDIX A}

Text Given to Subjects (both Online and In-Person) in Field Research

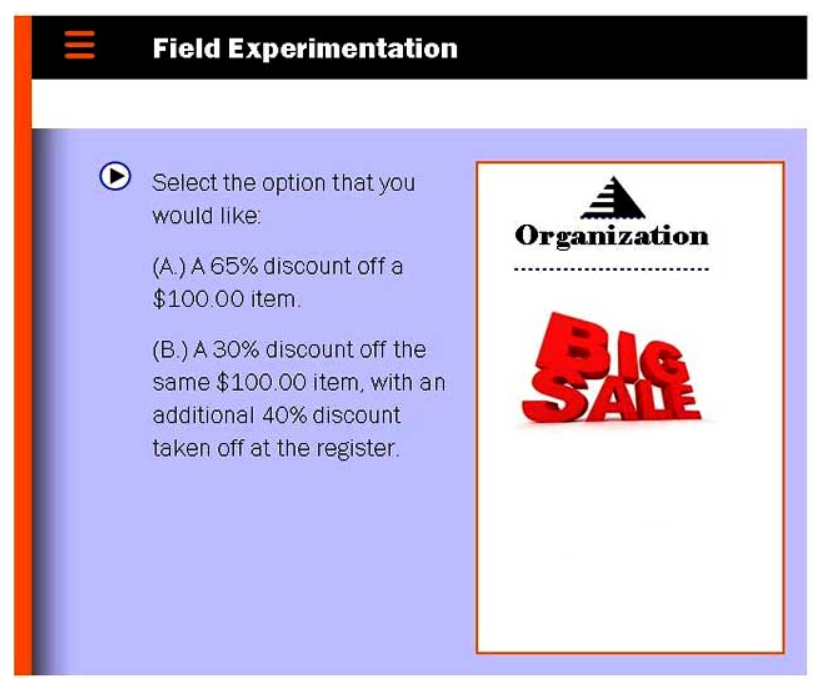

\section{REFERENCES}

[1] Simon HA. Models of bounded rationality, Vol. 3. Cambridge, MA: MIT Press, 1997.

[2] Kahneman D. Maps of bounded rationality: Psychology for behavioral economics. Am Econ Rev 2003; 93(5): 1449-75.

[3] Hoyer W. Consumer behavior, $5^{\text {th }}$ ed. Mason, OH: South-Western Cengage Learning 2009.

[4] Biswas D, Grau SL. Consumer choices under product option framing: Loss aversion principles or sensitivity to price differentials? Psychol Mark 2008; 25(5): 399-415.

[5] Tversky A, Kahneman D. The framing of decisions and the psychology of choice. Science 1981; 211: 453-8.

[6] Reder M. Rational choice: The contrast between economics and psychology. University of Chicago Press, Chicago, IL 1987.

[7] Berkman H. Consumer behavior. Chicago, IL: NTC Publishing Group, 1997.

[8] Murphy J. Advertising and marketing communication management. New York, NY: Dryden Press, 1993.

[9] Kahneman D, Tversky A. Choices, values and frames. Am Psychol 1984; 39: 341-50.

[10] Gilbride TJ, Guiltinan JP, Urbany JE. Framing effects in mixed price bundling. Mark Lett 2008; 19: 125-39.

[11] Janiszewski C, Cunha M. The influence of price discount framing on the evaluation of a product bundle. J Consumer Res 2004; 30: 534-46.

[12] Ariely D. Predictably irrational. New York, NY: Harper Collins Publishers, 2008.

[13] Suri R, Anderson RE, Kotlov V. The use of 9-ending prices: Contrasting the USA and Poland. Eur J Mark 2004; 38(1/2): 56-72. 
[14] Anderson ET, Simester D. Effects of $\$ 9$ price endings on retail sales: Evidence from field experiments. Quant Mark Econ 2003; 1(1): 93-110.

[15] Gendall P, Holdershaw J, Garland R. The effect of odd pricing on demand. Eur J Mark 1997; 31(11/12): 799-813.

[16] Kotler P, Keller KL. Marketing management, $13^{\text {th }}$ ed. Upper Saddle River, NJ: Pearson Education, Inc. 2009.
[17] Stafford M. Advertising, promotion and new media. New York, NY: M.E. Sharpe, Inc. 2005.

[18] Landa JT, Wang XT. Bounded rationality of economic man: Decision making under ecological, social, and institutional constraints. J Bioecon 2001; 3: 217-35.

Received: December 24, 2010

Revised: March 24, 2011

Accepted: March 31, 2011

(C) Deng and Deng; Licensee Bentham Open.

This is an open access article licensed under the terms of the Creative Commons Attribution Non-Commercial License (http://creativecommons.org/licenses/by-nc/3.0/) which permits unrestricted, non-commercial use, distribution and reproduction in any medium, provided the work is properly cited. 